\title{
Assessment of Inhibited Alveolar-Capillary Membrane Structural Development and Function in Bronchopulmonary Dysplasia
}

\author{
Shawn K. Ahlfeld ${ }^{\star}$ and Simon J. Conway \\ Developmental Biology and Neonatal Medicine Program, HB Wells Center for Pediatric \\ Research, Indiana University School of Medicine, Indianapolis, Indiana
}

\section{Abstract}

Bronchopulmonary dysplasia (BPD) is a chronic lung disease of extreme prematurity and is defined clinically by dependence on supplemental oxygen due to impaired gas exchange. Optimal gas exchange is dependent on the development of a sufficient surface area for diffusion. In the mammalian lung, rapid acquisition of distal lung surface area is accomplished in neonatal and early adult life by means of vascularization and secondary septation of distal lung airspaces. Extreme preterm birth interrupts secondary septation and pulmonary capillary development and ultimately reduces the efficiency of the alveolar-capillary membrane. Although pulmonary health in BPD infants rapidly improves over the first few years, persistent alveolar-capillary membrane dysfunction continues into adolescence and adulthood. Preventative therapies have been largely ineffective, and therapies aimed at promoting normal development of the air-blood barrier in infants with established BPD remain largely unexplored. The purpose of this review will be: (1) to summarize the histological evidence of aberrant alveolar-capillary membrane development associated with extreme preterm birth and BPD, (2) to review the clinical evidence assessing the long-term impact of BPD on alveolar-capillary membrane function, and (3) to discuss the need to develop and incorporate direct measurements of functional gas exchange into clinically relevant animal models of inhibited alveolar development.

\section{Keywords}

bronchopulmonary dysplasia; mouse; neonatal lung morphogenesis; hyperoxia; lung function; diffusing capacity

\section{Introduction}

Bronchopulmonary dysplasia (BPD), a chronic lung disease associated with extreme prematurity ( $<30$ weeks gestation), affects 12,000 infants annually and results in chronically impaired lung function (Aukland et al., 2009; Fawke et al., 2010; Stoll et al., 2010; Jobe, 2011; Gough et al., 2012; Cazzato et al., 2013; Gibson and Doyle, 2013). Clinically, it is manifested by reduced gas exchange resulting in a dependence on supplemental oxygen

(C) 2014 Wiley Periodicals, Inc.

"Correspondence to: Shawn K. Ahlfeld, 1044 West Walnut Street, Indiana University School of Medicine, Indianapolis, IN 46202. skahlfel@iupui.edu. 
(Jobe and Bancalari, 2001). Although necessary to sustain life following extreme preterm birth, mechanical ventilation and supplemental oxygen can disrupt the intricate molecular networks responsible for normal distal lung development; the result is inhibited subdivision of distal airspaces, blunted pulmonary microvasculature growth, and attenuated expansion of the alveolar-capillary membranes (Husain et al., 1998; Bhatt et al., 2001; Thibeault et al., 2003, 2004). Despite minimization of the most overt signs of lung disease, BPD survivors often exhibit reductions in exercise tolerance and diffusing capacity into adolescence (Vrijlandt et al., 2006; Balinotti et al., 2010; Fakhoury et al., 2010; Fawke et al., 2010; Hayes et al., 2011), suggesting persistent functional deficits of the alveolar-capillary membrane. Moreover, in animal models that closely resemble the pathological features of human BPD, brief exposure of the neonatal developing lung to hyperoxia is associated with enduring impairment in alveolarization, reduced pulmonary arterial density, and premature death (Roberts et al., 1983; Randell et al., 1989; Thibeault et al., 1990; Yee et al., 2009, 2011). Thus, even limited insults during critical periods of development are likely to have subtle yet significant direct long-lasting effects on the ultimate function of the alveolarcapillary membrane complex.

Although they have significantly advanced our understanding of BPD pathogenesis, preventative therapies derived from animal models of inhibited alveolar development have failed to translate into significant reductions in BPD incidence. While BPD is diagnosed clinically as oxygen dependency resulting from reduced gas exchange, therapies tested in animal models have been evaluated largely on their ability to restore alveolar structure without assessing normalization of functional gas exchange; it is largely unknown if improved lung structure equates to a functional recovery of gas exchange sufficient to reduce dependence on supplemental oxygen. Additionally, the ability to therapeutically promote normal alveolar-capillary growth once it has been inhibited has been underexplored.

The purpose of this review is to summarize the effects of preterm birth and BPD on the structural development of the alveolar-capillary membrane. Furthermore, it will discuss the long-term functional deficits of the alveolar-capillary membrane observed in infants, children, and adults with BPD. Finally, it will highlight the need for the design of clinically relevant animal models of inhibited alveolar-capillary membrane development that incorporate techniques to assess the capacity of the alveolar-capillary membrane to perform functional gas exchange.

\section{Inhibition of Alveolar-Capillary Membrane Development in BPD}

Efficient functional gas exchange at birth requires the development of a sufficient pulmonary alveolar-capillary membrane. In human lung development, the rudimentary alveolar-capillary membrane is formed by the thinning of distal lung mesenchyme and rapid expansion of intraacinar capillaries during the canalicular stage. The canalicular stage occurs in human infants between 18 and 26 weeks gestation and results in the close apposition of capillaries to the distal airspace lining (Burri, 2006; Kimura and Deutsch, 2007). Following the canalicular stage, expansion of distal ventilatory units occurs from 24 to 38 weeks gestation during the saccular stage. The saccular lung is characterized by further increases in 
gas-exchange surface area by means of the branching, lengthening, and widening of the distal air sacs with additional thinning of the surrounding mesenchyme (Wert, 2004; Rutter and Post, 2008). Further differentiation and thinning of the epithelial cells into maturing Type-I epithelial cells further decreases the distance required for gas-exchange. The prenatal development of the alveolar-capillary membrane in the human fetus has been described (Thibeault et al., 2004), and reviewed by Hislop (Hislop, 2002). Examining the lungs of 30 infants that died of nonpulmonary causes between 22 and 40 weeks gestation, Thibeault et al. quantified the development of the volume density of distal lung parenchymal vessels contributing to the alveolar-capillary membrane (Thibeault et al., 2004). They found a rapid, $800 \%$ increase in alveolar-capillary membrane per surface area of distal lung, which paralleled the increase in lung parenchyma volume and surface area, from 22 to 32 weeks gestation. Thereafter, the rate slowed during saccular lung development resulting in a $30 \%$ increase from 32 weeks to birth. Thus, a profound increase in the alveolar-capillary membrane surface area prepares the infant for the transition to postnatal gas exchange.

While prenatal distal airspace development provides a sufficient air-blood barrier for neonatal life, normal growth and development from infancy to adulthood requires an additional significant increase in the surface area for gas exchange. Continued parenchymal growth and subdivision of primary distal lung saccules by secondary septation during the alveolar stage of lung development begins as early as 29 to 30 weeks of gestation and results in a 20-fold increase in alveolar-capillary membrane area (Hislop et al., 1986; Thibeault et al., 2004). Secondary alveolar septation is largely a postnatal event, as alveolar number increases from an estimated 20 million at birth (Dunnill, 1962), to nearly 500 million in the adult (Ochs et al., 2004).

The limit of viability is dependent on the development of an air-blood barrier capable of sufficient gas exchange. By accelerating the thinning of the mesenchyme prematurely, antenatal steroid exposure promotes establishment of a minimally functional alveolarcapillary membrane capable of supporting gas exchange and survival of infants as early as 22 to 23 weeks of gestation (Whitsett et al., 1987; Ballard, 1989; Roberts and Dalziel, 2006). The result has been a significant increase in survival of infants born extremely preterm (Fanaroff et al., 2003; Stoll et al., 2010). Because the majority of infants that survive extreme preterm birth develop BPD (Stoll et al., 2010), the prevalence of BPD has increased.

Histological examinations of extremely preterm infants that have died with BPD have demonstrated an inhibition of normal alveolar-capillary membrane development. As discussed above, the canalicular and saccular stages of lung development are characterized by a rapid expansion of air-blood barrier by means of development of the distal airspaces and vasculature. Infants at greatest risk for BPD are born before 28 weeks gestation (Stoll et al., 2010), suggesting that interference with the canalicular and saccular stages of lung development contribute to disease pathophysiology. Hislop et al. described a series of 33 infants born 25 to 38 weeks of gestation that were ventilated in the neonatal period (Hislop et al., 1987). The infants died between 1 week and 14 months and their lung morphology was compared with a control group of 68 infants matched for gestation age. Although all infants displayed some growth of distal airspace surface area, ventilated preterm infants, 
especially the most premature, demonstrated generalized emphysematous changes due to an inhibition of alveolar septation. Likewise, Hussain et al. reported on 14 surfactant-treated extremely preterm infants that died of BPD at 6 to 7 months of age (one at 7 years) and described homogenous emphysematous changes with reduced alveolar septation (Husain et al., 1998). Thibeault et al. reviewed autopsy findings in 35 infants (mean gestational age 2526 weeks and birthweight <800 grams); the majority of infants were delivered following antenatal steroids, received surfactant replacement therapy, and had been ventilated for the majority of their postnatal life. Lungs of infants with severe chronic lung disease were composed of enlarged alveoli with blunted secondary septa. Although increased from what would be expected at gestational age at birth, compared with controls the rate at which the density of distal lung parenchyma vessels increased was much slower. Additionally, microvascular diameter and septal thickness were significantly increased; vessels were far from the airspace surface resulting in a thickened alveolar-capillary membrane (Thibeault et al., 2004). An additional report in five surfactant-era extremely preterm infants that died of BPD from 28 to 44 weeks postconceptional age found similar results: an overall reduction in number of pulmonary capillaries with the remaining vessels being dysmorphic and far from the septal surface (Bhatt et al., 2001).

\section{Persistently Limited Airflow and Impaired Alveolar-Capillary Function in Survivors of BPD}

Although the severity of respiratory symptoms improves rapidly over the first few years, survivors of BPD have persistently reduced lung function. Compared with those born at term, symptoms of asthma and airway obstruction are more prevalent in those born extremely preterm, especially those with a history of BPD. At 11 years of age, extremely preterm children with a history of BPD from the EPICure cohort (a prospective analysis of all surviving infants born at $ک 25$ weeks gestation in Europe in 1995) were twice as likely (28 vs. $13 \%$ ) to have a diagnosis of asthma and over $50 \%$ had abnormal baseline spirometry (even if clinically asymptomatic) (Fawke et al., 2010). Children with a history of BPD had obstruction to airflow at the level of the small airways, as evidenced by lower $(80 \%$ predicted) forced expiratory volume in one second ( $\mathrm{FEV}_{1}$, a measure of airflow obstruction) combined with significantly reduced (58\% predicted) $\mathrm{FEF}_{25-75}$ (the average forced expiratory flow during exhalation of the mid (25-75\%) portion of the forced vital capacity, a measure of airflow through the small conducting airways). Analysis to control for the effect of age, sex, and body size confirmed that $66 \%$ of children with BPD had abnormally low lung function at baseline (indicated by $\mathrm{FEV}_{1}$ or $\mathrm{FEF}_{25-75} \mathrm{z}$-scores $\leq-1.96$ ) versus only $9 \%$ of controls. Despite significant improvement of airway obstruction following bronchodilator therapy in $32 \%$ of children with BPD, spirometry remained abnormal and significantly decreased. Multiple reports in children and adolescents cared for in the pre- and postsurfactant era have found similar evidence of persistent airways disease. A metaanalysis of 18 observational studies that measured pulmonary function at 7 to 18 years of age consistently found that those with a history of BPD had persistent, significant impairment in $\mathrm{FEV}_{1}$ (Gibson and Doyle, 2013). Finally, high resolution chest CT (HRCT) has been used to evaluate BPD survivors for persistent parenchymal abnormalities. HRCT was obtained in 74 subjects 10 to 18 years of age that were born at $<28$ weeks gestation, 
weighed <1000 grams at birth, and were cared for between 1982 and 1991 . The results were correlated with measures of pulmonary function $\left(\mathrm{FEV}_{1}, \mathrm{FEF}_{25-75}\right.$, and total lung capacity [TLC]) (Aukland et al., 2009). Of the entire cohort, 28\% had a diagnosis of moderate-severe BPD. Abnormal HRCT findings, consisting of minor linear and subpleural opacities, were common: $86 \%$ of the cohort had abnormalities suggestive of persistent structural lung injury. Those with moderate-severe BPD were significantly more likely to have an abnormal scan, and there was a significant correlation between abnormal HRCT and previous duration of supplemental oxygen and mechanical ventilation. HRCT scores were able to predict presence of airflow obstruction, as evidenced by significant reductions FEV 1 . Similar associations have been observed in other cohorts of young adult survivors of BPD, predominately in the presurfactant era, and have encountered up to a $50 \%$ incidence of emphysematous changes on HRCT (Howling et al., 2000; Wong et al., 2008, 2011).

\section{Utility of the Carbon Monoxide Diffusing Capacity (DLco) in Evaluating Pulmonary Gas Exchange}

Although symptoms of airway obstruction are prevalent in BPD survivors, BPD is defined by dysfunction of the alveolar-capillary membrane resulting in the need for supplemental oxygen (Jobe and Bancalari, 2001; Ehrenkranz et al., 2005). Clinical measures of pulmonary gas exchange are, therefore, useful for determining the long-term consequences of impaired alveolar septal and vascular development on alveolar-capillary function. The carbon monoxide diffusing capacity (DLco) is the most sensitive measure of alveolar-capillary gas transfer. The majority of parenchymal lung diseases are associated with a diminished diffusing capacity. Reductions in the DLco reliably predict exercise-induced hypoxemia in chronic obstructive pulmonary disease (COPD) and interstitial lung disease (Owens et al., 1984; Risk et al., 1984; Ries et al., 1988). DLco has been measured in several cohorts of children and young adults born extremely preterm and, as discussed below, those with a history of BPD have consistently lower diffusing capacity. Several basic principles that contribute to derivation of the reported values associated with measurements of DLco must be understood for proper clinical interpretation. Excellent reviews for performing and interpreting DLco have recently been published (Macintyre et al., 2005; Hughes and Pride, 2012;), and the key concepts required to interpret DLco in BPD pathophysiology will be discussed here.

\section{KEY CONCEPTS IN CLINICAL INTERPRETATION OF THE DLCO}

The measured difference in the inhaled and exhaled concentrations of a carbon monoxide (CO) -containing test gas is used to determine DLco. During a single breath hold near TLC, the rate at which $\mathrm{CO}$ is removed from the alveolar space is exponential and directly proportional to the breath-holding time. The slope at which $\mathrm{CO}$ concentration declines over the breath hold is known as the rate constant for carbon monoxide uptake from alveolar gas (Kco). The DLco is the product of Kco and the alveolar volume accessible to gas exchange $\left(\mathrm{V}_{\mathrm{A}}\right)$. Because the $\mathrm{V}_{\mathrm{A}}$ represents the available alveolar volume (and, therefore, alveolarcapillary surface area) for CO uptake, the DLco is directly proportional to $\mathrm{V}_{\mathrm{A}}$. After correcting for the partial pressure of CO in the test gas, DLco is expressed as the alveolar $\mathrm{CO}$ uptake per minute per $\mathrm{mmHg} \mathrm{Pco}(\mathrm{ml} / \mathrm{min} / \mathrm{mmHg})$. The sum of $\mathrm{CO}$ transfer occurs in 
two phases (Fig. 1), expressed as the equation $1 / \mathrm{D}_{\mathrm{L}}=1 / \mathrm{D}_{\mathrm{M}}+1 / \tau \cdot \mathrm{Vc}$ (Roughton and Forster, 1957; Hughes and Pride, 2012). The first phase of CO transfer is across the alveolarcapillary membrane $\left(\mathrm{D}_{\mathrm{M}}\right.$, membrane diffusing capacity). The second phase is determined by the rate at which $\mathrm{CO}$ undergoes reaction with hemoglobin on the red blood cell in a given pulmonary capillary volume $(\tau \cdot \mathrm{Vc})$. Total alveolar surface area and the thickness of the alveolar-capillary membrane determine $\mathrm{D}_{\mathrm{M}}$, while the density of pulmonary capillaries, the cardiac output, the alveolar $\mathrm{P}_{\mathrm{O} 2}$, and the hemoglobin concentration affect $\tau$. $\mathrm{Vc}$.

The $\mathrm{V}_{\mathrm{A}}$ is determined by measuring the difference between the inhaled and exhaled concentrations of an inert, nonabsorbable gas (usually Helium or Neon) that is diluted in the alveolar gas during a single breath hold near TLC. The $\mathrm{V}_{\mathrm{A}}$ increases with TLC and both values are directly proportional to sex and body length. Normally, the $\mathrm{V}_{\mathrm{A}}$ underestimates the TLC secondary to anatomical dead space and incomplete homogenization of the test and alveolar gases. Incomplete alveolar expansion due to sub-optimal inspiratory effort will also reduce $\mathrm{V}_{\mathrm{A}}$. Localized or diffuse loss of alveolar units (bulla, atelectasis, and interstitial fibrosis-all of which can be seen in BPD) will also result in a lower than predicted $\mathrm{V}_{\mathrm{A}}$. Additionally, severe intrapulmonary airflow obstruction or significant heterogeneity of alveolar ventilation results in incomplete dilution of test gas and underestimation of $\mathrm{V}_{\mathrm{A}}$ (Verbanck et al., 2008). A reduction in the ratio of $\mathrm{V}_{\mathrm{A}}$ to TLC (measured by independent means) can signify if a reduction in $\mathrm{V}_{\mathrm{A}}$ is secondary to misdistribution of test gas.

To assess the efficiency of the alveolar-capillary membrane for CO transfer, the DLco is often expressed as the carbon monoxide diffusing capacity per unit of alveolar volume, or $\mathrm{DLco} / \mathrm{V}_{\mathrm{A}}$. DLco $/ \mathrm{V}_{\mathrm{A}}$ (herein referred to as Kco, expressed as $\mathrm{ml} / \mathrm{min} / \mathrm{mmHg} / \mathrm{L}$ ) directly reflects the quality of alveolar-capillary gas transfer. It is important to determine both the DLco (the total capacity for CO transfer) and the Kco (the efficiency of CO transfer for a given $\mathrm{V}_{\mathrm{A}}$ ) to fully understand the clinical implications of an altered diffusing capacity. For example, a decrease in DLco can result from a decrease in Kco (the rate of CO uptake from the alveoli, determined by $\mathrm{D}_{\mathrm{M}}$ and $\tau \cdot \mathrm{V}$ ) ) or a decrease in $\mathrm{V}_{\mathrm{A}}$ (the volume "accessible" for $\mathrm{CO}$ transfer). As the lung volume (and, therefore, $\mathrm{V}_{\mathrm{A}}$ ) falls, the DLco is reduced due to the decrease in alveolar volume accessible for gas exchange. However, the same reduction in $\mathrm{V}_{\mathrm{A}}$ results in an even greater increase in the Kco, because a constant $\mathrm{Vc}$ will result in a rise in $\mathrm{Vc}_{\mathrm{c}} / \mathrm{V}_{\mathrm{A}}$ (Stam et al., 1991; Johnson, 2000). Physiologically, this is explained by the consistency of the pulmonary blood flow over a range of lung volumes. Because the $D_{M}$ is constant, the stability of the $\mathrm{Vc}$ results in the same degree of gas transfer at lower $\mathrm{V}_{\mathrm{A}}$. Thus, the efficiency of gas transfer (the Kco) improves.

Determination of Kco, $\mathrm{V}_{\mathrm{A}}$ and TLC are required for one to correctly interpret the clinical etiology of a reduced DLco (Table 1). In the case of BPD, the described pathology includes some degree of mild interstitial fibrosis, reduced alveolar surface area due to inhibited secondary alveolar septation, and decreased capillary volume secondary to diminished pulmonary vascular development (Hislop et al., 1987; Husain et al., 1998; Bhatt et al., 2001; Thibeault et al., 2004). Thus, one would anticipate that a reduced DLco would be accompanied by a normal $\mathrm{V}_{\mathrm{A}}$ and $\mathrm{V}_{\mathrm{A}}$ /TLC ratio, normal TLC, and low Kco (secondary to impairments in both $\mathrm{D}_{\mathrm{M}}$ and $\mathrm{Vc}$ components). 


\section{IMPAIRED DIFFUSING CAPACITY IN BPD SURVIVORS}

DLco has been measured in infants, children, and young adults born extremely premature in the postsurfactant era to determine the impact that BPD has on alveolar-capillary membrane function (Table 2). In a single center study, DLco, $\mathrm{V}_{\mathrm{A}}$ and $\mathrm{DLco} / \mathrm{V}_{\mathrm{A}}$ in 39 infants diagnosed with BPD (mean gestational age $\sim 26$ weeks and mean birthweight $\sim 800$ grams) were compared with 61 age-matched term controls at an average of 11 months postconceptional age (Balinotti et al., 2010). BPD infants were on supplemental oxygen for an average of 82 days following birth but were clinically stable off oxygen at the time of examination. Infants with BPD had similar $\mathrm{V}_{\mathrm{A}}$ compared with controls, but despite being clinically well, had significantly lower DLco and DLco/ $/ \mathrm{V}_{\mathrm{A}}$. Given that $\mathrm{V}_{\mathrm{A}}$ was similar in both groups, the fall in $\mathrm{DLco} / \mathrm{V}_{\mathrm{A}}$ would be indicative of a deficit in membrane surface area $\left(\mathrm{D}_{\mathrm{M}}\right)$, alveolar capillary volume $(\tau \cdot \mathrm{Vc})$, or both. Thus, the results corroborated the histopathological findings reported in postsurfactant BPD (Husain et al., 1998). Likewise, in 62 children 7 to 10 years of age born extremely premature and diagnosed with BPD, two separate studies reported significant reductions of $\sim 10$ to $15 \%$ in DLco and DLco/ $/ \mathrm{V}_{\mathrm{A}}$ (Korhonen et al., 2004; Kaplan et al., 2012). In an additional cohort of 22 extremely preterm children (8-9 years old) with a history of BPD, DLco and DLco/ $\mathrm{V}_{\mathrm{A}}$ were significantly reduced, and $\mathrm{DLco} / \mathrm{V}_{\mathrm{A}}$ fell proportionately with the length of exposure to supplemental oxygen (Cazzato et al., 2013). Finally, 11-year pulmonary outcomes of children from the EPICure cohort reported similar $\mathrm{V}_{\mathrm{A}}$ but reduced DLco and DLco/ $/ \mathrm{V}_{\mathrm{A}}$ as well as diminished exercise capacity in children with a history of BPD (Welsh et al., 2010; Lum et al., 2011). It is important to note that the severity of BPD represented by these reports was predominately mild-moderate which may explain the small reductions observed. However, the fact that impaired diffusing capacity was measurable in "healthy" survivors speaks to the chronic, insidious nature of BPD.

Several case series of adolescents and adults born extremely premature in the presurfactant era have also investigated diffusing capacity in survivors of BPD. In 21 adults (17-33 years of age) born between 1980 and 1987 with mean gestational age of 27 weeks and mean birthweight 895 grams that required supplemental oxygen at 36 weeks postconceptional age, DLco was compared with abnormality on HRCT (Wong et al., 2008). Radiological evidence of emphysema was present in $84 \%$ of those with a history of BPD. The DLco was also abnormal in $84 \%$ of subjects and was significantly reduced from expected (z-score -5.04 ). There was no significant correlation between abnormalities on CT and impairment in DLco, underscoring the independent utility of DLco to adequately assess gas transfer function. In 10 children born at an average gestational age of 30 weeks and average birth weight of 1350 grams between 1985 and 1987 with a history of BPD, DLco and DLco/ $\mathrm{V}_{\mathrm{A}}$ were significantly reduced at baseline (Mitchell and Teague, 1998). Importantly, DLco failed to increase as expected during exercise and fell below pre-exercise levels during the immediate rest period. Children with BPD also experienced significantly more desaturation events during exercise. The authors speculated that the findings were suggestive of inadequate increases in right ventricular output and/or long-term deficits in alveolar-capillary development. Diminished maximal exercise capacity associated with reductions of DLco have been observed in several additional cohorts of adolescents and adults cared for in the presurfactant era, although often with a normal DLco/ $\mathrm{V}_{\mathrm{A}}$ at rest (Hakulinen et al., 1996; Vrijlandt et al., 2006; Lovering et al., 2013). It is difficult to interpret the clinical implication 
of the discrepancy, however, as $\mathrm{V}_{\mathrm{A}}$ was infrequently reported. Additionally, these cohorts, including the 18-year follow-up study of the infants that comprised Northway's originally description of BPD (Northway et al., 1990), likely represent the classical form of BPD typified by thickened interstitium, alveolar destruction, and patchy areas of bullous emphysema (Stocker, 1986; Husain et al., 1998). It is plausible that the low $\mathrm{DLco} / \mathrm{V}_{\mathrm{A}}$ may be secondary to reduced $\mathrm{V}_{\mathrm{A}}$ from non-homogenous gas mixing or inadequate alveolar expansion, or there may have been a compensatory increase in pulmonary capillary volume, as has been described in two autopsy reports (Thibeault et al., 2004; De Paepe et al., 2006).

\section{Evidence for Potential for Catch-up Alveolarization in Established BPD}

Given that survivors of BPD have significant, persistent small airways disease, impaired exercise capacity, and reduced diffusing capacity, there is a need for novel therapies that promote development of alveolar-capillary surface area. Additionally, although they experience the anticipated incremental development of lung function during childhood and adolescence, survivors of BPD continue to follow a trajectory parallel but consistently below that of term-born peers (Vollsaeter et al., 2013). Indeed, some have associated BPD with an accelerated decline in lung function by late adolescence (Doyle et al., 2006). If extremely preterm infants with BPD never obtain peak lung function, the natural loss of lung function that occurs with age may result in premature disability. Preventative strategies have been largely disappointing and have failed to lessen the burden of BPD (Laughon et al., 2009b; Jobe, 2011) and, therefore, alternative strategies should be explored to encourage optimal "catch-up" growth in those with established BPD.

An improved understanding of the timeline of human alveolar development has broadened the potential window for "catch-up" alveolarization. Early investigations of alveolar development in the 1960s described a rapid increase in alveolar number over the first 2 years, resulting in $\sim 50 \%$ of the adult number (Dunnill, 1962). Based on data obtained from two additional children and compared with historic adult estimates, the author proposed that the alveolar number of $\sim 300$ million was attained by 8 years of age. A subsequent study of two children ( 5 and 11 years of age) estimated similar alveolar numbers of $\sim 303$ to 336 million and supported the theory that adult alveolar numbers were present by late childhood (Davies and Reid, 1970). Additional reports presented evidence that continued to compress the window of significant alveolar development; by the 1980s it was accepted that by 2 to 3 years of age alveolarization was essentially complete (Thurlbeck, 1982; Hislop et al., 1986; Zeltner and Burri, 1987; Zeltner et al., 1987). However, these conclusions were based on relatively small numbers of infants, potentially biased morphometric methods, and an assumption that adult alveolar number was $~ 300$ million. It was also noted that total alveolar number correlated with length and displayed significant inter-individual variability (Angus and Thurlbeck, 1972). More recently, unbiased methods of alveolar counting have increased the estimated adult alveolar number to $\sim 80$ million (Ochs et al., 2004). Evidence of late alveolarization in rodents (equivalent to late adolescence in humans) has questioned the requirement for a double-capillary microvasculature for septation by demonstrating emergence of new septa well after microvascular maturation (Mund et al., 2008; Schittny et al., 2008). Using helium-3 ( $\left.{ }^{3} \mathrm{He}\right)$ MRI to assess alveolar size noninvasively in 109 healthy subjects from 7 to 21 years of age, Narayanan et al. calculated at least a twofold increase in 
alveolar number from childhood to early adulthood (Narayanan et al., 2012). Given that adult alveolar size is relatively constant (Ochs et al., 2004) and that lung volume increases three- to four-fold from 7 years to adulthood, they reasoned that if no additional alveoli were formed, increased lung volume could only occur by means of similar increases in individual alveolar size. However, ${ }^{3} \mathrm{He}-\mathrm{MRI}$ analysis revealed a significantly smaller than expected increase in alveolar size, suggesting that neoalveolarization must have occurred. The sum of these studies suggests that a wider window of postnatal alveolar development exists during which one could promote optimal alveolar-capillary development.

Infants at greatest risk for BPD (those $<28$ weeks gestation at birth) are born with a saccular lung (Kimura and Deutsch, 2007; Stoll et al., 2010). Acute lung injury secondary to hyperoxia, mechanical ventilation, and pre/postnatal infections are encountered in the first several days of life. It is hypothesized that these early insults imposed by extreme preterm birth can initiate, within hours to days, the processes that ultimately lead to development of BPD (Jobe, 2011). Indeed, by 14 to 21 days the clinical condition can be used to reliably predict an infant's likelihood to fulfill diagnostic criteria at 36 weeks postconceptional age for moderate-severe BPD (Laughon et al., 2009a, 2011; Bose et al., 2011). Although highly variable, many infants that develop BPD slowly recover from their initial illness and show significant clinical improvement by 40 weeks postconceptional age. The EPICure study has provided valuable insight into the natural course of respiratory health during the first 6 years following hospital discharge with a diagnosis of BPD (Hennessy et al., 2008). Of the 308 infants that survived to 30 months of age, $74 \%$ had a diagnosis of moderate-severe BPD and $36 \%$ of those required supplemental oxygen at discharge. The need for supplemental oxygen decreased rapidly over the first year of age, and by 12 months corrected age over $75 \%$ no longer required oxygen. Length of home oxygen therapy correlated with the degree of prematurity: the most immature infants required supplemental oxygen significantly longer. For the entire cohort of extremely preterm children, $64 \%$ required re-hospitalization in the first 30 months of age and one third required $\geq 3$ hospitalizations for respiratory illnesses. Infants requiring supplemental oxygen at discharge were nearly 3 times more likely to require multiple re-admissions. However, by 6 years of age, hospitalization was infrequent and comparable to children born at term. Thus, the clinical course of BPD is typified by significant, acute lung injury over the first several weeks or months followed by a period of persistent clinical improvement over the first few years of age. Although biologically plausible, it is speculated that clinical improvement is due to continued development of the alveolar-capillary membrane. Therefore, strategies that promote secondary alveolar septation and normal capillary development (and, thereby, speed or optimize recovery of functional gas exchange) during this window of rapid alveolar development could potentially reduce dependence on supplemental oxygen, increase pulmonary reserve, and decrease hospitalization re-admission rates. However, studies to evaluate therapies aimed at improving alveolar-capillary development and function in established BPD are lacking. 


\section{Optimizing the Clinical Relevance of Animal Models of Inhibited Alveolar- Capillary Membrane Development}

To test strategies that promote optimal alveolar-capillary membrane structural and functional development, animal models must be carefully designed to recapitulate the timing of injury and recovery in a manner that is clinically relevant. While no perfect animal model exists, because rodents are naturally born with saccular lungs, continuous exposure of neonates to hyperoxia can inhibit alveolar septal and vascular development and reliably recapitulate many of the features of human BPD (Warner et al., 1998; Husain et al., 1998; Bhatt et al., 2001; Thibeault et al., 2004; van Haaften et al., 2009; Buczynski et al., 2013a). We have used this strategy to effectively inhibit murine secondary alveolar septation. When newborn pups are exposed to hyperoxia continuously from birth onward, we observe evidence of inhibited septal development as early as postnatal day (P) 4 to P7 (Fig. 2). Additionally, from birth to full adult growth, the human and rodent lung undergoes similar fold-change increases in lung volume and alveolar-capillary surface area for gas exchange (Zeltner et al., 1987). Starting on P4, the rodent lung experiences rapid secondary alveolar septation and contains roughly half the number of adult alveoli by P14 to P21 (Mund et al., 2008; Schittny et al., 2008). A similar period of rapid alveolar development in the human lung is estimated to occur within 18 to 24 months after birth (Dunnill, 1962). Given that the majority of initial injury and clinical symptomatology associated with human BPD is observed during saccular and bulk alveolar lung development, a developmentally appropriate rodent model would be one that limits injury to the periods of saccular and early bulk alveolar development ( $\mathrm{P} 0$ through $\mathrm{P} 7-14$ ), and then allows for a period of repair and attempted compensatory expansion of alveolar-capillary surface area.

A developmentally appropriate model of BPD, consisting of acute hyperoxic injury during initial alveolar septation followed by a period of recovery in room air, has been welldescribed in neonatal rodents (Roberts et al., 1983; Shaffer et al., 1987; Randell et al., 1989, 1990; Thibeault et al., 1990; Lin et al., 2005). Whereas room air control animals experienced a 16-fold increase in alveolar number from birth to $\mathrm{P} 7$, exposure of neonatal rats to $100 \%$ oxygen from birth through P7 resulted in an acute arrest of alveolar septal and microvascular vascular development (Roberts et al., 1983; Randell et al., 1989). Upon return to the room air environment there was resumption of alveolar development, but at P21 oxygen-exposed animals had 25\% fewer alveoli resulting in significantly reduced alveolar surface area (Randell et al., 1989). Although there was an initial, step-wise reduction in pulmonary microvasculature that correlated with the oxygen concentration, at 21 to 40 days animals recovered in room air had markedly increased alveolar capillary density suggestive of a compensatory angiogenic response (Roberts et al., 1983; Randell et al., 1990). This response may be short-lived, however, because in animals recovered out to 40 to 60 days, reductions in alveolar-capillary surface area and total alveolar number persisted (Shaffer et al., 1987; Thibeault et al., 1990). Additionally, oxygen-exposed lungs displayed distal extension of the muscular coat into the microvasculature and right ventricular hypertrophy (RVH) indicative of pulmonary hypertension (Shaffer et al., 1987; Thibeault et al., 1990). 
O'Reilly et al. have extensively investigated the long-term effects of hyperoxic lung injury limited to the murine postnatal saccular lung. Neonatal mice exposed to increasing oxygen concentrations (40 to $100 \%$ ) from birth to $\mathrm{P} 4$, followed by a return to room air until 8 weeks of age, displayed inhibition of alveolar development that was proportionate to the level of oxygen (Yee et al., 2009). Recovered mice exhibited several of the features observed in human BPD, including excessive inflammatory response to Influenza infection, decreased pulmonary elastance, increased tissue compliance, and enlarged, simplified distal airspaces due to reduced secondary septation (O'Reilly et al., 2008, 2012; Yee et al., 2009; Buczynski et al., 2012, 2013b). Although no measurable changes in alveolar microvascular development were present at 8 weeks, a separate cohort allowed to recover for up to 67 weeks of age had striking loss of pulmonary microvasculature, muscularization of pulmonary arterioles, development of RVH, and shortened life span (Yee et al., 2011). Interestingly, the defects in alveolar development were no longer apparent, as evidenced by normalization of alveolar airspace size. Thus, even hyperoxia limited to relatively short periods of saccular-alveolar lung development are capable of durably inhibiting alveolarcapillary structure.

From the rodent studies discussed above, it is clear that even brief hyperoxia during saccular and early alveolar development can persistently impair adult lung structure and airway function. During the acute hyperoxia exposure, there is essentially complete arrest of further saccular and alveolar development. Upon returning to room air, alveolar septal and capillary development resumes and there are compensatory gains in alveolar-capillary structure. However, even with prolonged recovery in a normal environment, alveolar-capillary membrane structure is abnormal. BPD following extreme preterm birth follows a similar pattern. Extremely preterm infants are born with saccular lungs and exposed to hyperoxia (relative to the normally hypoxic in utero environment) while they adapt to the ex utero environment. While highly variable, the most intense respiratory support often is required during the first few postnatal months, which normally overlap with the onset of early alveolar septation. Many infants with BPD have clinically improved by 40 weeks postconceptional age; infants with moderate to severe BPD that require further oxygen support at home experience significant clinical improvement over the first 2 postnatal years (Hennessy et al., 2008). Because recovery occurs during the normal period of bulk alveolarization, it is assumed that improved lung growth and development allows the rapid addition of new alveolar-capillary units. Although clinically improved, however, BPD survivors have persistent functional and, most likely, structural defects through adulthood. Thus, by restricting neonatal hyperoxia to saccular and early alveolar development and then allowing for a period of recovery in normoxia, rodent models have recapitulated several of the clinical aspects of human BPD.

\section{Assessing Alveolar-Capillary Membrane Function in Animal Models of Inhibited Alveolarization}

Although rodent models have significantly improved our understanding of BPD pathogenesis, functional analysis of the structural improvements has unfortunately lagged behind and translation into effective therapeutic strategies has generally been disappointing. 
The most notable example would be the recent experience with inhaled nitric oxide (iNO). Well-designed, thoughtful studies done predominately by Abman et al. demonstrated that vascular endothelial growth factor (VEGF) pathway signaling was required for the alveolarcapillary membrane to develop normally: inhibiting VEGF signaling in neonatal rodents by means of VEGF receptor blockade or down-regulating VEGF protein expression by means of hyperoxic exposure resulted in significantly inhibited alveolar-capillary development reminiscent of human BPD (Jakkula et al., 2000; Le Cras et al., 2002; Kunig et al., 2005; Balasubramaniam et al., 2007). Further studies suggested that iNO was a down-stream mediator of VEGF signaling and served a vital role in alveolar-capillary development (Tang et al., 2004). Ultimately, it was shown that supplemental iNO provided during or immediately following acute neonatal lung injury was capable of restoring normal alveolarcapillary development in rodents (Tang et al., 2004; Lin et al., 2005; ter Horst et al., 2007), baboons (McCurnin et al., 2005), and lambs (Bland et al., 2005). These novel discoveries were rapidly translated into several clinical trials to test the ability of iNO to prevent BPD following extremely preterm birth (Van Meurs et al., 2005; Ballard et al., 2006; Kinsella et al., 2006). Despite several well-designed trials, the results were disappointing: iNO failed to reduce significantly and consistently the rate of BPD (Barrington and Finer, 2010). Consequently, an expert panel has recommended against the routine use of iNO as a strategy to prevent BPD (Cole et al., 2011).

The discordance between the apparent effectiveness in animal studies and the measurable utility of iNO to prevent BPD raises important questions concerning the applicability of animal models to the human disease. Significantly, although rodent models rely on improved alveolar-capillary structure to test effectiveness of a therapy, interventional trials rely on improved alveolar-capillary function. Although one would expect them to be highly correlated, there is a dearth of evidence in animal models that improved alveolar-capillary structure correlates to improved alveolar-capillary function. Despite improvement in morphometric indices of alveolar-capillary membrane development, closer inspection of alveolar histology often suggests incomplete, albeit improved, preservation. Although there may be many reasons why iNO failed to reduce the incidence BPD, it is possible that the measured improvement in alveolar-capillary structure in the animal model did not equate to a fully functional alveolar-capillary membrane. Because BPD is a clinical rather than structural diagnosis, it is unknown whether infants exposed to iNO experienced improved lung structure. Therefore, to adequately assess the effectiveness of a potential intervention, application of techniques to measure alveolar-capillary membrane function in preclinical models is needed.

A simple, reproducible method that measures alveolar-capillary membrane function has recently been described and applied to rodent models of pulmonary disease (Fallica et al., 2011). Mitzner and colleagues used the diffusing properties of carbon monoxide (CO) and neon $(\mathrm{Ne})$ gases to directly measure pulmonary alveolar-capillary membrane functional capacity. The technique involves inflating the rodent lung to TLC with a test gas containing known concentrations of $\mathrm{CO}$ (which is highly diffusible across the alveolar capillary membrane) and $\mathrm{Ne}$ (which cannot permeate the alveolar-capillary membrane and is merely diluted). Following a specified hold time, the gas is withdrawn and concentrations of $\mathrm{CO}$ and $\mathrm{Ne}$ are determined using a bench-top gas chromatographer. The ratio of $\mathrm{CO}$ uptake to 
Ne dilution is used to calculate the diffusing factor of carbon monoxide (DFco), a dimensionless variable that is similar to the clinically measured DLco. Although significantly reduced in bleomycin-induced pulmonary fibrotic disease and elastase-induced emphysema, DFco has not been used to determine the functional outcomes in preclinical rodent models of BPD.

\section{Conclusions}

Despite technological advances in neonatal intensive care resulting in improved survival, BPD continues to affect the majority of infants born extremely preterm. Survivors of BPD experience relatively rapid improvements in their clinical condition during the first few years of life. However, persistent limitations in airflow, exercise capacity, and alveolarcapillary membrane diffusing capacity suggest that survivors of BPD have life-long impairments. Thus, there is potential that as survivors of BPD experience the natural decline in lung function with age, they could prematurely reach debilitating levels of lung dysfunction. Animal models of inhibited alveolar septation have revolutionized our understanding of BPD pathogenesis but translation into clinically effective therapies has been disappointing. While BPD is defined clinically by the need for supplemental oxygen due to abnormal alveolar-capillary function, animal models of inhibited alveolar development are defined by abnormal alveolar-capillary structure. Because assessments of functional gas exchange are lacking in preclinical models, one could speculate that promising BPD therapies may have improved alveolar-capillary structure without adequately restoring alveolar-capillary function. Novel techniques that measure alveolarcapillary membrane function should, therefore, be incorporated into clinically relevant animal models of BPD to determine if indices of alveolar-capillary structural development adequately correlate with restoration of functional gas exchange. Finally, recent evidence points to an expanded window of alveolar-capillary development beyond infancy and into early adulthood. Therapies aimed at promoting recovery of optimal alveolar-capillary development during this normal period of rapid alveolarization may prove more effective than previous strategies to prevent BPD. Developmentally appropriate animal models that test a therapy's ability to restore both alveolar-capillary structural and functional development following limited, acute lung injury are, therefore, greatly needed.

\section{Acknowledgments}

Studies were supported, in part, by KL2 RR025760 (A. Shekhar, PI); as well as Riley Children's Foundation, the Indiana University Department of Pediatrics (Neonatal-Perinatal Medicine) and National Institutes of Health HL115619.

\section{References}

Angus GE, Thurlbeck WM. Number of alveoli in the human lung. J Appl Physiol. 1972; 32:483-485. [PubMed: 5026496]

Aukland SM, Rosendahl K, Owens CM, et al. Neonatal bronchopulmonary dysplasia predicts abnormal pulmonary HRCT scans in long-term survivors of extreme preterm birth. Thorax. 2009; 64:405-410. [PubMed: 19158126]

Balasubramaniam V, Mervis CF, Maxey AM, et al. Hyperoxia reduces bone marrow, circulating, and lung endothelial progenitor cells in the developing lung: implications for the pathogenesis of 
bronchopulmonary dysplasia. Am J Physiol Lung Cell Mol Physiol. 2007; 292:L1073-L1084. [PubMed: 17209139]

Balinotti JE, Chakr VC, Tiller C, et al. Growth of lung parenchyma in infants and toddlers with chronic lung disease of infancy. Am J Resp Crit Care Med. 2010; 181:1093-1097. [PubMed: 20133928]

Ballard PL. Hormonal regulation of pulmonary surfactant. Endocr Rev. 1989; 10:165-181. [PubMed: 2666118]

Ballard RA, Truog WE, Cnaan A, et al. Inhaled nitric oxide in preterm infants undergoing mechanical ventilation. N Engl J Med. 2006; 355:343-353. [PubMed: 16870913]

Barrington KJ, Finer N. Inhaled nitric oxide for respiratory failure in preterm infants. Cochrane Database Syst Rev. 2010 CD000509.

Bhatt AJ, Pryhuber GS, Huyck H, et al. Disrupted pulmonary vasculature and decreased vascular endothelial growth factor, flt-1, and tie-2 in human infants dying with bronchopulmonary dysplasia. Am J Respir Crit Care Med. 2001; 164:1971-1980. [PubMed: 11734454]

Bland RD, Albertine KH, Carlton DP, MacRitchie AJ. Inhaled nitric oxide effects on lung structure and function in chronically ventilated preterm lambs. Am J Resp Crit Care Med. 2005; 172:899_ 906. [PubMed: 15976381]

Bose C, Laughon M, Allred EN, et al. Blood protein concentrations in the first two postnatal weeks that predict bronchopulmonary dysplasia among infants born before the 28th week of gestation. Pediatr Res. 2011; 69:347-353. [PubMed: 21150694]

Buczynski BW, Maduekwe ET, O'Reilly MA. The role of hyperoxia in the pathogenesis of experimental BPD. Semin Perinatol. 2013a; 37:69-78. [PubMed: 23582960]

Buczynski BW, Yee M, Martin KC, et al. Neonatal hyperoxia alters the host response to influenza A virus infection in adult mice through multiple pathways. Am J Physiol Lung Cell Mol Physiol. 2013b; 305:L282-L290. [PubMed: 23748535]

Buczynski BW, Yee M, Paige, et al. Lung development and the host response to influenza A virus are altered by different doses of neonatal oxygen in mice. Am J Physiol Lung Cell Mol Physiol. 2012; 302:L1078-L1087. [PubMed: 22408042]

Burri PH. Structural aspects of postnatal lung development - alveolar formation and growth. Biol Neonate. 2006; 89:313-322. [PubMed: 16770071]

Cazzato S, Ridolfi L, Bernardi F, et al. Lung function outcome at school age in very low birth weight children. Pediatr Pulmonol. 2013; 48:830-837. [PubMed: 23129340]

Cole FS, Alleyne C, Barks JD, et al. NIH consensus development conference statement: inhaled nitricoxide therapy for premature infants. Pediatrics. 2011; 127:363-369. [PubMed: 21220405]

Davies G, Reid L. Growth of the alveoli and pulmonary arteries in childhood. Thorax. 1970; 25:669681. [PubMed: 5533319]

De Paepe ME, Mao Q, Powell J, et al. Growth of pulmonary microvasculature in ventilated preterm infants. Am J Resp Crit Care Med. 2006; 173:204-211. [PubMed: 16210670]

Doyle LW, Faber B, Callanan C, et al. Bronchopulmonary dysplasia in very low birth weight subjects and lung function in late adolescence. Pediatrics. 2006; 118:108-113. [PubMed: 16818555]

Dunnill MS. Postnatal growth of the lung. Thorax. 1962; 17:329-333.

Ehrenkranz RA, Walsh MC, Vohr BR, et al. Validation of the national institutes of health consensus definition of bronchopulmonary dysplasia. Pediatrics. 2005; 116:1353-1360. [PubMed: 16322158]

Fakhoury KF, Sellers C, Smith EO, et al. Serial measurements of lung function in a cohort of young children with bronchopulmonary dysplasia. Pediatrics. 2010; 125:e1441-e1447. [PubMed: 20439591]

Fallica J, Das S, Horton M, Mitzner W. Application of carbon monoxide diffusing capacity in the mouse lung. J Appl Physiol. 2011; 110:1455-1459. [PubMed: 21310888]

Fanaroff AA, Hack M, Walsh MC. The NICHD neonatal research network: changes in practice and outcomes during the first 15 years. Semin Perinatol. 2003; 27:281-287. [PubMed: 14510318]

Fawke J, Lum S, Kirkby J, et al. Lung function and respiratory symptoms at 11 years in children born extremely preterm: the EPICure study. Am J Resp Crit Care Med. 2010; 182:237-245. [PubMed: 20378729] 
Gibson AM, Doyle LW. Respiratory outcomes for the tiniest or most immature infants. Semin Fetal Neonatal Med. 2013 doi: 10.1016/j.siny.2013.10.006. [Epub ahead of print].

Gough A, Spence D, Linden M, et al. General and respiratory health outcomes in adult survivors of bronchopulmonary dysplasia: a systematic review. Chest. 2012; 141:1554-1567. [PubMed: 22116801]

Hakulinen AL, Jarvenpaa AL, Turpeinen M, Sovijarvi A. Diffusing capacity of the lung in school-aged children born very preterm, with and without bronchopulmonary dysplasia. Pediatr Pulmonol. 1996; 21:353-360. [PubMed: 8927461]

Hayes D Jr, Meadows JT Jr, Murphy BS, et al. Pulmonary function outcomes in bronchopulmonary dysplasia through childhood and into adulthood: implications for primary care. Prim Care Respir J. 2011; 20:128-133. [PubMed: 21336467]

Hennessy EM, Bracewell MA, Wood N, et al. Respiratory health in pre-school and school age children following extremely preterm birth. Arch Dis Childhood. 2008; 93:1037-1043. [PubMed: 18562451]

Hislop AA. Airway and blood vessel interaction during lung development. J Anat. 2002; 201:325-334. [PubMed: 12430957]

Hislop AA, Wigglesworth JS, Desai R. Alveolar development in the human fetus and infant. Early Hum Dev. 1986; 13:1-11. [PubMed: 3956418]

Hislop AA, Wigglesworth JS, Desai R, Aber V. The effects of preterm delivery and mechanical ventilation on human lung growth. Early Hum Dev. 1987; 15:147-164. [PubMed: 3608888]

Howling SJ, Northway WH Jr, Hansell DM, et al. Pulmonary sequelae of bronchopulmonary dysplasia survivors: high-resolution CT findings. AJR Am J Roentgenol. 2000; 174:1323-1326. [PubMed: 10789786]

Hughes JM, Pride NB. Examination of the carbon monoxide diffusing capacity (DL(CO)) in relation to its KCO and VA components. Am J Respir Crit Care Med. 2012; 186:132-139. [PubMed: 22538804]

Husain AN, Siddiqui NH, Stocker JT. Pathology of arrested acinar development in postsurfactant bronchopulmonary dysplasia. Hum Pathol. 1998; 29:710-717. [PubMed: 9670828]

Jakkula M, Le Cras TD, Gebb S, et al. Inhibition of angiogenesis decreases alveolarization in the developing rat lung. Am J Physiol Lung Cell Mol Physiol. 2000; 279:L600-L607. [PubMed: 10956636]

Jobe AH. The new bronchopulmonary dysplasia. Curr Opin Pediatr. 2011; 23:167-172. [PubMed: 21169836]

Jobe AH, Bancalari E. Bronchopulmonary dysplasia. Am J Respir Crit Care Med. 2001; 163:17231729. [PubMed: 11401896]

Johnson DC. Importance of adjusting carbon monoxide diffusing capacity (DLCO) and carbon monoxide transfer coefficient (KCO) for alveolar volume. Respir Med. 2000; 94:28-37. [PubMed: 10714476]

Kaplan E, Bar-Yishay E, Prais D, et al. Encouraging pulmonary outcome for surviving, neurologically intact, extremely premature infants in the postsurfactant era. Chest. 2012; 142:725-733. [PubMed: 22423043]

Kimura J, Deutsch GH. Key mechanisms of early lung development. Pediatr Dev Pathol. 2007; 10:335-347. [PubMed: 17929994]

Kinsella JP, Cutter GR, Walsh WF, et al. Early inhaled nitric oxide therapy in premature newborns with respiratory failure. N Engl J Med. 2006; 355:354-364. [PubMed: 16870914]

Korhonen P, Laitinen J, Hyodynmaa E, Tammela O. Respiratory outcome in school-aged, very-lowbirth-weight children in the surfactant era. Acta Paediatr. 2004; 93:316-321. [PubMed: 15124832]

Kunig AM, Balasubramaniam V, Markham NE, et al. Recombinant human VEGF treatment enhances alveolarization after hyperoxic lung injury in neonatal rats. Am J Physiol Lung Cell Mol Physiol. 2005; 289:L529-L535. [PubMed: 15908474]

Laughon M, Allred EN, Bose C, et al. Patterns of respiratory disease during the first 2 postnatal weeks in extremely premature infants. Pediatrics. 2009a; 123:1124-1131. [PubMed: 19336371]

Laughon MM, Brian Smith P, Bose C. Prevention of bronchopulmonary dysplasia. Semin Fetal Neonatal Med. 2009b; 14:374-382. [PubMed: 19736053] 
Laughon MM, Langer JC, Bose CL, et al. Prediction of bronchopulmonary dysplasia by postnatal age in extremely premature infants. Am J Respir Crit Care Med. 2011; 183:1715-1722. [PubMed: 21471086]

Le Cras TD, Markham NE, Tuder RM, et al. Treatment of newborn rats with a VEGF receptor inhibitor causes pulmonary hypertension and abnormal lung structure. Am J Physiol Lung Cell Mol Physiol. 2002; 283:L555-L562. [PubMed: 12169575]

Lin YJ, Markham NE, Balasubramaniam V, et al. Inhaled nitric oxide enhances distal lung growth after exposure to hyperoxia in neonatal rats. Pediatr Res. 2005; 58:22-29. [PubMed: 15879297]

Lovering AT, Laurie SS, Elliott JE, et al. Normal pulmonary gas exchange efficiency and absence of exercise-induced arterial hypoxemia in adults with bronchopulmonary dysplasia. J Appl Physiol. 2013; 115:1050-1056. 1985. [PubMed: 23869070]

Lum S, Kirkby J, Welsh L, et al. Nature and severity of lung function abnormalities in extremely preterm children at 11 years of age. Eur Respir J. 2011; 37:1199-1207. [PubMed: 20947682]

Macintyre N, Crapo RO, Viegi G, et al. Standardisation of the single-breath determination of carbon monoxide uptake in the lung. Eur Respir J. 2005; 26:720-735. [PubMed: 16204605]

McCurnin DC, Pierce RA, Chang LY, et al. Inhaled NO improves early pulmonary function and modifies lung growth and elastin deposition in a baboon model of neonatal chronic lung disease. Am J Physiol Lung Cell Mol Physiol. 2005; 288:L450-L459. [PubMed: 15591412]

Mitchell SH, Teague WG. Reduced gas transfer at rest and during exercise in school-age survivors of bronchopulmonary dysplasia. Am J Respir Crit Care Med. 1998; 157(Pt 1):1406-1412. [PubMed: 9603115]

Mund SI, Stampanoni M, Schittny JC. Developmental alveolarization of the mouse lung. Dev Dyn. 2008; 237:2108-2116. [PubMed: 18651668]

Narayanan M, Owers-Bradley J, Beardsmore CS, et al. Alveolarization continues during childhood and adolescence: new evidence from helium-3 magnetic resonance. Am J Respir Crit Care Med. 2012; 185:186-191. [PubMed: 22071328]

Northway WH Jr, Moss RB, Carlisle KB, et al. Late pulmonary sequelae of bronchopulmonary dysplasia. N Engl J Med. 1990; 323:1793-1799. [PubMed: 2247118]

O'Reilly MA, Marr SH, Yee M, et al. Neonatal hyperoxia enhances the inflammatory response in adult mice infected with influenza a virus. Am J Respir Crit Care Med. 2008; 177:1103-1110. [PubMed: 18292469]

O'Reilly MA, Yee M, Buczynski BW, et al. Neonatal oxygen increases sensitivity to influenza A virus infection in adult mice by suppressing epithelial expression of ear1. Am J Pathol. 2012; 181:441451. [PubMed: 22677423]

Ochs M, Nyengaard JR, Jung A, et al. The number of alveoli in the human lung. Am J Respir Crit Care Med. 2004; 169:120-124. [PubMed: 14512270]

Owens GR, Rogers RM, Pennock BE, Levin D. The diffusing capacity as a predictor of arterial oxygen desaturation during exercise in patients with chronic obstructive pulmonary disease. N Engl J Med. 1984; 310:1218-1221. [PubMed: 6709028]

Randell SH, Mercer RR, Young SL. Postnatal growth of pulmonary acini and alveoli in normal and oxygen-exposed rats studied by serial section reconstructions. Am J Anat. 1989; 186:55-68. [PubMed: 2782288]

Randell SH, Mercer RR, Young SL. Neonatal hyperoxia alters the pulmonary alveolar and capillary structure of 40-day-old rats. Am J Pathol. 1990; 136:1259-1266. [PubMed: 2356858]

Ries AL, Farrow JT, Clausen JL. Pulmonary function tests cannot predict exercise-induced hypoxemia in chronic obstructive pulmonary disease. Chest. 1988; 93:454-459. [PubMed: 3125012]

Risk C, Epler GR, Gaensler EA. Exercise alveolar-arterial oxygen pressure difference in interstitial lung disease. Chest. 1984; 85:69-74. [PubMed: 6690254]

Roberts D, Dalziel S. Antenatal corticosteroids for accelerating fetal lung maturation for women at risk of preterm birth. Cochrane Database Syst Rev. 2006; 3 CD004454.

Roberts RJ, Weesner KM, Bucher JR. Oxygen-induced alterations in lung vascular development in the newborn rat. Pediatr Res. 1983; 17:368-375. [PubMed: 6856398]

Roughton FJ, Forster RE. Relative importance of diffusion and chemical reaction rates in determining rate of exchange of gases in the human lung, with special reference to true diffusing capacity of 
pulmonary membrane and volume of blood in the lung capillaries. J Appl Physiol. 1957; 11:290302. [PubMed: 13475180]

Rutter, M.; Post, M. Molecular basis for normal and abnormal lung development. In: Bancalari, E., editor. The newborn lung: neonatology questions and controversies. Saunders; Philadelphia: 2008. p. 3-41.

Schittny JC, Mund SI, Stampanoni M. Evidence and structural mechanism for late lung alveolarization. Am J Physiol Lung Cell Mol Physiol. 2008; 294:L246-L254. [PubMed: 18032698]

Shaffer SG, O’Neill D, Bradt SK, Thibeault DW. Chronic vascular pulmonary dysplasia associated with neonatal hyperoxia exposure in the rat. Pediatr Res. 1987; 21:14-20. [PubMed: 3642429]

Stam H, Kreuzer FJ, Versprille A. Effect of lung volume and positional changes on pulmonary diffusing capacity and its components. J Appl Physiol. 1991; 71:1477-1488. [PubMed: 1757373]

Stocker JT. Pathologic features of long-standing "healed" bronchopulmonary dysplasia: a study of 28 3- to 40-month-old infants. Hum Pathol. 1986; 17:943-961. [PubMed: 3639056]

Stoll BJ, Hansen NI, Bell EF, et al. Neonatal outcomes of extremely preterm infants from the nichd neonatal research network. Pediatrics. 2010; 126:443-456. [PubMed: 20732945]

Tang JR, Markham NE, Lin YJ, et al. Inhaled nitric oxide attenuates pulmonary hypertension and improves lung growth in infant rats after neonatal treatment with a VEGF receptor inhibitor. Am J Physiol Lung Cell Mol Physiol. 2004; 287:L344-L351. [PubMed: 15064225]

ter Horst SA, Walther FJ, Poorthuis BJ, et al. Inhaled nitric oxide attenuates pulmonary inflammation and fibrin deposition and prolongs survival in neonatal hyperoxic lung injury. Am J Physiol Lung Cell Mol Physiol. 2007; 293:L35-L44. [PubMed: 17384081]

Thibeault DW, Mabry S, Rezaiekhaligh M. Neonatal pulmonary oxygen toxicity in the rat and lung changes with aging. Pediatr Pulmonol. 1990; 9:96-108. [PubMed: 2399053]

Thibeault DW, Mabry SM, Norberg M, et al. Lung microvascular adaptation in infants with chronic lung disease. Biol Neonate. 2004; 85:273-282. [PubMed: 14739556]

Thibeault DW, Truog WE, Ekekezie II. Acinar arterial changes with chronic lung disease of prematurity in the surfactant era. Pediatr Pulmonol. 2003; 36:482-489. [PubMed: 14618639]

Thurlbeck WM. Postnatal human lung growth. Thorax. 1982; 37:564-571. [PubMed: 7179184]

van Haaften T, Byrne R, Bonnet S, et al. Airway delivery of mesenchymal stem cells prevents arrested alveolar growth in neonatal lung injury in rats. Am J Respir Crit Care Med. 2009; 180:1131-1142. [PubMed: 19713449]

Van Meurs KP, Wright LL, Ehrenkranz RA, et al. Inhaled nitric oxide for premature infants with severe respiratory failure. N Engl J Med. 2005; 353:13-22. [PubMed: 16000352]

Verbanck S, Schuermans D, Van Malderen S, Vincken W, Thompson B. The effect of conductive ventilation heterogeneity on diffusing capacity measurement. J Appl Physiol. 2008; 104:10941100. 1985. [PubMed: 18276899]

Vollsaeter M, Roksund OD, Eide GE, et al. Lung function after preterm birth: development from midchildhood to adulthood. Thorax. 2013; 68:767-776. [PubMed: 23749815]

Vrijlandt EJ, Gerritsen J, Boezen HM, et al. Lung function and exercise capacity in young adults born prematurely. Am J Respir Crit Care Med. 2006; 173:890-896. [PubMed: 16456146]

Warner BB, Stuart LA, Papes RA, Wispe JR. Functional and pathological effects of prolonged hyperoxia in neonatal mice. Am J Physiol Lung Cell Mol Physiol. 1998; 275:L110-L117.

Welsh L, Kirkby J, Lum S, et al. The EPICure study: maximal exercise and physical activity in school children born extremely preterm. Thorax. 2010; 65:165-172. [PubMed: 19996340]

Wert, SE. Normal and abnormal structural development of the lung. In: Polin, RA.; Fox, WW.; Abman, SH., editors. Fetal and neonatal physiology. 3rd ed.. Saunders; Philadelphia: 2004. p. 783-792.

Whitsett JA, Weaver TE, Clark JC, et al. Glucocorticoid enhances surfactant proteolipid Phe and pVal synthesis and RNA in fetal lung. J Biol Chem. 1987; 262:15618-15623. [PubMed: 2445738]

Wong P, Murray C, Louw J, et al. Adult bronchopulmonary dysplasia: computed tomography pulmonary findings. J Med Imaging Radiat Oncol. 2011; 55:373-378. [PubMed: 21843172] 
Wong PM, Lees AN, Louw J, et al. Emphysema in young adult survivors of moderate-to-severe bronchopulmonary dysplasia. Eur Respir J. 2008; 32:321-328. [PubMed: 18385172]

Yee M, Chess PR, McGrath-Morrow SA, et al. Neonatal oxygen adversely affects lung function in adult mice without altering surfactant composition or activity. Am J Physiol Lung Cell Mol Physiol. 2009; 297:L641-L649. [PubMed: 19617311]

Yee M, White RJ, Awad HA, et al. Neonatal hyperoxia causes pulmonary vascular disease and shortens life span in aging mice. Am J Pathol. 2011; 178:2601-2610. [PubMed: 21550015]

Zeltner TB, Burri PH. The postnatal development and growth of the human lung. II. Morphology. Respir Physiol. 1987; 67:269-282. [PubMed: 3575906]

Zeltner TB, Caduff JH, Gehr P, et al. The postnatal development and growth of the human lung. I. Morphometry. Respir Physiol. 1987; 67:247-267. [PubMed: 3575905] 


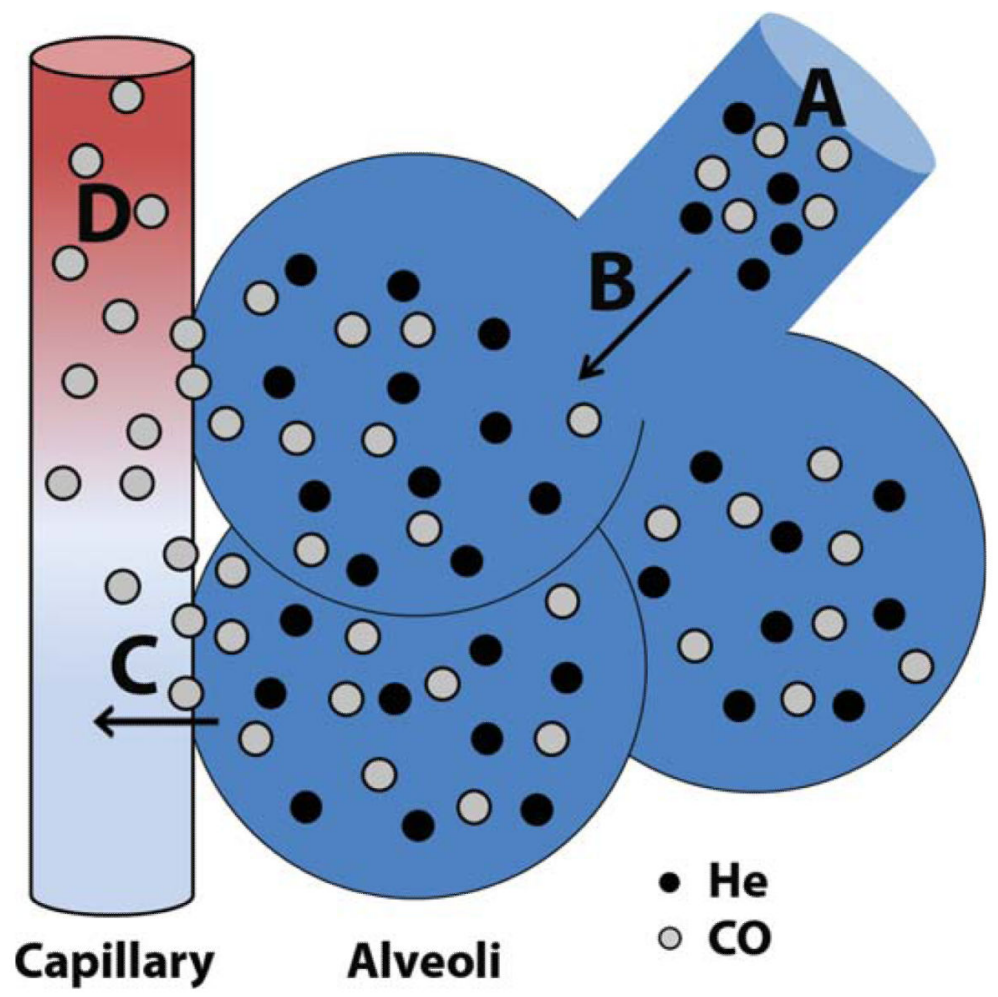

FIGURE 1.

Determination of alveolar volume and the carbon monoxide diffusing capacity by single breath hold. A: Inhalation of test gas containing a mixture of nondiffusible helium (closed circles) and highly diffusible carbon monoxide (open circles). B: During the single breath hold near total lung capacity, the test gas is rapidly diluted in the alveolar gas. Nonabsorbable helium remains within the alveolus, and its fractional dilution measured at exhalation determines the alveolar volume $\left(\mathrm{V}_{\mathrm{A}}\right)$. C,D: The rate of carbon monoxide uptake is determined by diffusion across the alveolar membrane $\left(\mathrm{D}_{\mathrm{M}}, \mathbf{C}\right)$, as well as diffusion into the available pulmonary capillary volume and the reaction with hemoglobin $(\tau \cdot \mathrm{Vc}, \mathbf{D})$. 

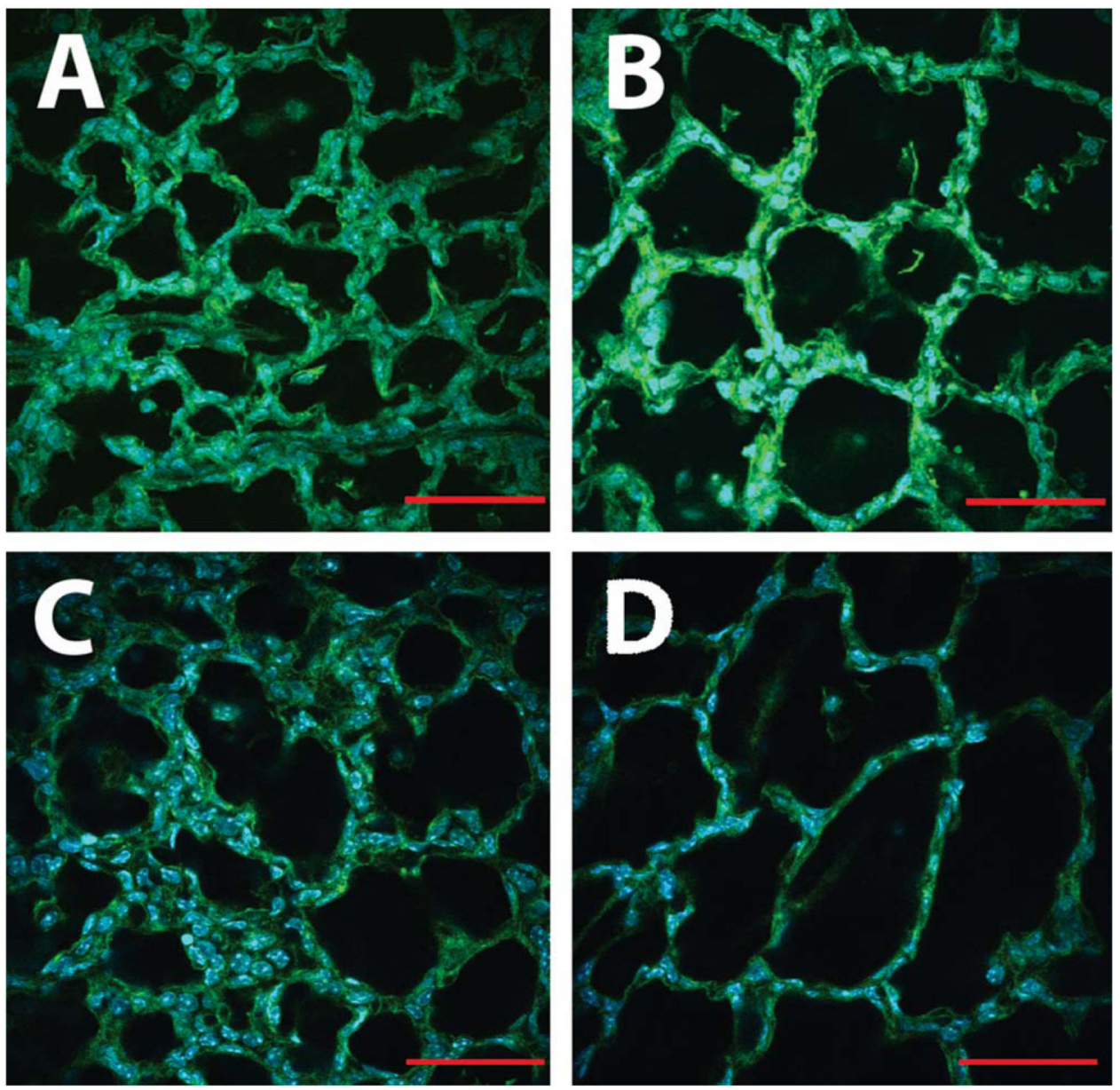

FIGURE 2.

Neonatal hyperoxia exposure inhibits murine alveolar development and mimics human BPD. Representative confocal micrographs of fixed, unprocessed lung in 4-day-old neonatal mice continuously exposed to room air (A) or 85\% hyperoxia (B) from birth. Even at this early stage, the oxygen-exposed lungs show enlarged, simplified airspaces compared with room air. By 7 days of age, continued hyperoxia exposure has arrested secondary alveolar septation, resulting in room air-exposed lungs (C) that are significantly more complex that those exposed to oxygen (D). Scale bars $=50 \mu \mathrm{m}$. 
TABLE 1

Potential Etiology of Low VA and Its Effect on Kco

\begin{tabular}{lccc} 
Condition & DLco & Kco & $\mathbf{V}_{\mathbf{A}}$ \\
\hline Inadequate inspiration & $\downarrow$ & $\uparrow$ & $\downarrow$ \\
\hline $\begin{array}{c}\text { Diffuse interstitial lung disease } \\
\text { (alveolar-capillary deficit) }\end{array}$ & $\downarrow$ & $\downarrow$ & $\downarrow$ \\
\hline $\begin{array}{l}\text { Emphysema (alveolar-capillary deficit) } \\
\begin{array}{c}\text { Bronchopulmonary dysplasia } \\
\text { (alveolar-capillary deficit) }\end{array}\end{array}$ & $\downarrow$ & $\downarrow \downarrow$ & $\leftrightarrow$ \\
\hline $\begin{array}{c}\text { Pulmonary hypertension } \\
\text { (effectively reduced Vc) }\end{array}$ & $\downarrow$ & $\downarrow$ & $\leftrightarrow$ \\
\hline
\end{tabular}

DLco, single-breath diffusing capacity for carbon monoxide; $\mathrm{DLco} / \mathrm{V}_{\mathrm{A}}$, carbon monoxide diffusing capacity per unit alveolar volume; $\mathrm{V}_{\mathrm{A}}$, alveolar volume; Vc, pulmonary capillary volume; $\downarrow$, decreased; $\downarrow \downarrow$, significantly decreased; $\uparrow$, increased; $\leftrightarrow$, no change. 
TABLE 2

\section{Carbon Monoxide Diffusing Capacity in Post-Surfactant-Era Survivors of BPD}

\begin{tabular}{|c|c|c|c|c|c|c|c|c|}
\hline Study & Age & $\mathbf{N}_{(\mathbf{B P D})}$ & $\mathbf{G A}_{(\mathbf{w k})}$ & $\mathbf{B W}_{(\mathrm{g})}$ & $\mathbf{N}_{(\text {Con })}$ & DLco & Kco & $\mathbf{V}_{\mathbf{A}}$ \\
\hline Balinotti et al. & $11.6 \mathrm{mo}$ & 39 & 26 & 870 & 61 & $-20.6 \%$ & $-10.2 \%$ & ND \\
\hline Korhonen et al. & $7 \mathrm{yr}$ & 34 & 27 & 951 & 34 & $-14.9 \%$ & $-10.8 \%$ & NR \\
\hline Cazzato et al. & $8-9 \mathrm{yr}$ & 22 & 26 & 840 & 46 & -1.17 (z-score) & -1.17 (z-score) & NR \\
\hline Kaplan et al. & $10 \mathrm{yr}$ & 28 & 26.2 & 821 & 23 & $-13.6 \%$ & $-7.2 \%$ & NR \\
\hline Welsh et al. & $11 \mathrm{yr}$ & 38 & 25 & 740 & 38 & -0.94 (z-score) & -0.73 (z-score) & NR \\
\hline
\end{tabular}

Results reported are for BPD vs. term control.

BPD, bronchopulmonary dysplasia; BW, birthweight; Con, controls (term); DLco, single-breath diffusing capacity for carbon monoxide; g, grams; GA, gestational age; Kco, rate constant for carbon monoxide uptake per unit barometric pressure; mo, month; N, number of subjects; ND, no significant difference; NR, not reported; VA, alveolar volume; yr, year. Values reported are mean values. 